\title{
Analysis of crystallographic orientation influence on thermal fatigue with delay of the single-crystal corset sample by means of thermo-elasto-visco-plastic modeling
}

\author{
Artem Savikovskii ${ }^{1,}{ }^{*}$, Artem Semenov ${ }^{1}$, and Leonid Getsov ${ }^{2}$ \\ ${ }^{1}$ Peter the Great Saint-Petersburg Polytechnic University, 194064, Polytechnicheskaya 29, Russia \\ ${ }^{2}$ Research and production association for research and design of power equipment I. I. Polzunova, \\ 194021, Polytechnicheskaya 24, Russia
}

\begin{abstract}
The influence of a delay time at the maximum temperature on the number of cycles before the macrocrack initiation for two thermal loading programs was investigated for single-crystal nickel-based superalloy VZhM4. An analytic approximation of a delay time influence was proposed. Comparison of the computational results and analytic formula on the basis of constitutive equations with the experimental data was performed for various single-crystal nickel-based superalloys and showed a good accuracy. The influence of crystallographic orientation of the corset sample on the thermal fatigue durability with delay times was investigated for various thermal loading programs and single-crystal nickel-based superalloys.
\end{abstract}

\section{Introduction}

Single-crystal nickel based superalloys $[1,2]$ are promising used for production of gas turbine engines (GTE) [3]. These materials have a pronounced anisotropy and temperature dependence of properties. Cracking in the turbine blades is caused often by thermal fatigue $[4,5]$. For the investigation of thermal fatigue durability under a wide range of temperatures with and without delay times the experiments are carried out on different types of samples, including corset (plane) specimen [4] on the installation developed in NPO CKTI [6] (see Fig. 1). Fixed in axial direction by means of two bolts with a massive foundation the corset sample (see Fig. 2) is heated periodically by passing electric current through it. The fixing of sample under heating leads to the high stress level and inelastic strain appearance. The local strain and stress concentration is observed in the central (working) part of sample. The FE simulation is required for the computation of inhomogeneous stress and inelastic strain fields.

\footnotetext{
${ }^{*}$ Corresponding author: temachess@yandex.ru
} 


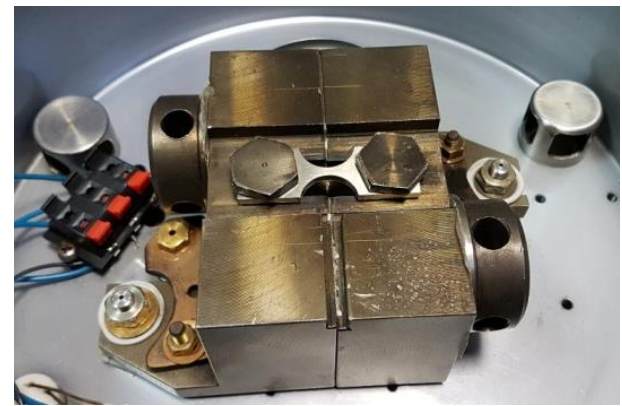

Fig. 1. Setup for thermal fatigue experimental investigations.

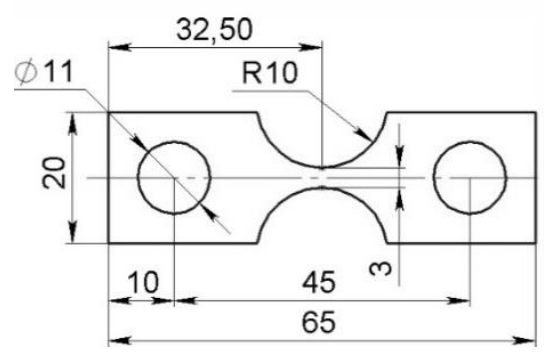

Fig. 2. Geometry of corset sample for thermal fatigue experiment.

The aim of the research is to study systematically the effect of delay at maximum temperature on the thermal fatigue durability on the base of the deformation criterion [7-11] for single crystal superalloys using the results of finite element (FE) simulation of full-scale experiments and results of analytical formulae and to study systematically the effect of crystallographic orientation on the thermal fatigue durability. The results of simulation and their verification are obtained for single-crystal nickel-based superalloy VZhM4.

\section{Methods}

Modeling of inelastic deformation in the corset samples has been performed with taking into account of the temperature dependence of all material properties, anisotropy of mechanical properties of single crystal sample, inhomogeneous temperature field, mechanical contacts between bolt and the specimen, between specimen and foundation, temperature expansion in the specimen.

The two FE formulations for the thermomechanical problem have been considered:

- $\quad$ with taking into account equipment;

- without taking into account equipment (simplified formulation [12] for the sample only).

The validity of the simplified formulation is based on the comparison with the results of full-scale formulation (with taking into account equipment), as well as on the comparison with the displacements of two markers measured in experiments. The problem was solved in a three-dimensional, quasi-static formulation. As boundary conditions the symmetry conditions were set: zero displacements on the $y$-axis on the xz plane and zero displacements on the $\mathrm{x}$-axis on the yz plane. On the lower side of the equipment zero displacements along the $\mathrm{x}$ and $\mathrm{z}$ axes were set. Tightening force was applied on the bolt cap. The temperature field distributions were set from the experimental data at maximum and minimum temperature with linear interpolation in time [13]. The results of finite element heat conduction simulations $[13,14]$ consistent with experimental temperature field distributions.

The mechanical properties for alloy VZHM4 were taken from the paper [15] are presented in Table 1. The mechanical properties of bolts are taken for pearlitic steel [16]. Used material properties consistent with considered in [17,18].

Table 1. Mechanical properties of VZHM4 used in simulations [15].

\begin{tabular}{|c|c|c|c|c|c|c|c|}
\hline $\boldsymbol{T}$ & ${ }^{\mathbf{0}} \mathbf{C}$ & $\mathbf{2 0}$ & $\mathbf{7 0 0}$ & $\mathbf{8 0 0}$ & $\mathbf{9 0 0}$ & $\mathbf{1 0 0 0}$ & $\mathbf{1 0 5 0}$ \\
\hline$E_{001}$ & $\mathrm{MPa}$ & 130000 & 101000 & 96000 & 91000 & 86000 & 82000 \\
\hline$\nu$ & - & 0.39 & 0.42 & 0.422 & 0.425 & 0.428 & 0.43 \\
\hline$\alpha$ & $1 / \mathrm{K}$ & $1.11 \cdot 10^{-5}$ & $1.68 \cdot 10^{-5}$ & $1.74 \cdot 10^{-5}$ & $1.87 \cdot 10^{-5}$ & $2.1 \cdot 10^{-5}$ & $2.3 \cdot 10^{-5}$ \\
\hline$\sigma_{Y 001}$ & $\mathrm{MPa}$ & 846 & 950 & - & - & - & 820 \\
\hline
\end{tabular}




\begin{tabular}{|c|c|c|c|c|c|c|c|}
\hline$n$ & - & 8 & 8 & 8 & 8 & 8 & 8 \\
\hline$A$ & $\mathrm{MPa}^{-n} s^{-1}$ & $1 \cdot 10^{-42}$ & $3 \cdot 10^{-31}$ & $1 \cdot 10^{-29}$ & $1 \cdot 10^{-28}$ & $2 \cdot 10^{-27}$ & $1 \cdot 10^{-26}$ \\
\hline
\end{tabular}

In simplified formulation (see Fig. 3) we consider only the sample without equipment, in which zero displacements on the symmetry planes $\mathrm{xz}$ and $\mathrm{yz}$ were set, the outer face of the sample parallel to the symmetry plane $\mathrm{xz}$ was fixed in the direction of the axis $\mathrm{x}$. To exclude solid body motions, a number of points on this face were also fixed in the direction of the $y$ and $\mathrm{z}$ axes.

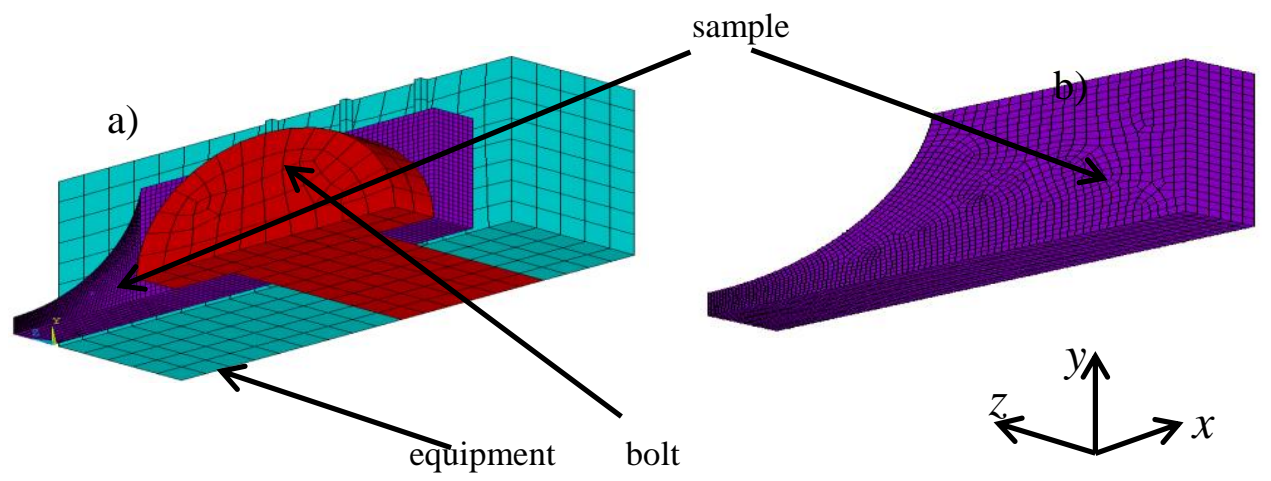

Fig. 3. Finite-element models in mechanical problem: a) with taking into account equipment, (1/4 of structure due to symmetry); b) without taking into account equipment (simplified formulation), (1/4 of structure due to symmetry).

Fig. 4 shows distributions of plastic strain intensity for two different temperature loading programs after 7 cycles (for VZHM4 the length of the sample is $42 \mathrm{~mm}$ ).

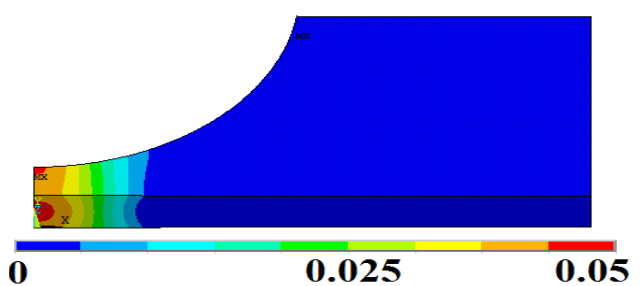

a)

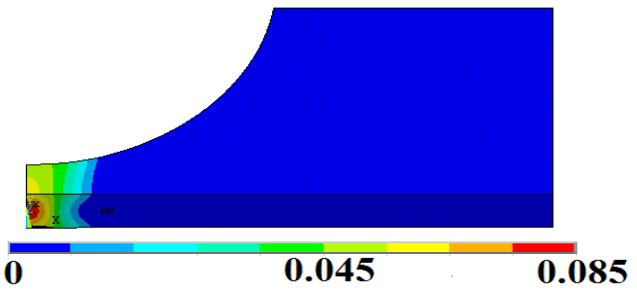

b)

Fig. 4. Distributions of plastic strain intensity for a) superalloy VZhM4, $T=700 \div 1050{ }^{\circ} \mathrm{C}$; b) VZhM4, $T=500 \div 1050{ }^{\circ} \mathrm{C}$ after 7 cycles.

The full effective length for superalloy VZhM4 for several temperature modes was $42 \mathrm{~mm}$ [13]. In the FE simulations the full length of the specimen for all alloys was taken to be $40 \mathrm{~mm}$.

Simulation of inelastic cyclic deformation of corset samples were performed with using of the FE program PANTOCRATOR [19], which allows to apply the micromechanical (physical) models of plasticity and creep for single crystals [20-22]. The micromechanical plasticity model accounting 12 octahedral slip systems with lateral and nonlinear kinematic hardening [20] was used in the FE computation for single crystal alloy. FE computations were carried out for a part of a corset sample (simplified FE model with half-effective length of sample equal $20 \mathrm{~mm}$, see Fig. 3b). The temperature boundary conditions were set from the experimental data at maximum and minimum temperature with linear interpolation in time. 
The influence of the delay at maximum temperature and the influence of crystallographic orientation on the number of cycles to the formation of macrocrack is analyzed in the range from $1 \mathrm{~min}$ to 1 hour for the cyclic loading regimes (see, for example, Fig. 9b) with:

- maximum temperature of $1050^{\circ} \mathrm{C}$ and a temperature range of $350^{\circ} \mathrm{C}$;

- maximum temperature of $1050^{\circ} \mathrm{C}$ and a temperature range of $550{ }^{\circ} \mathrm{C}$;

The heating times in the cycle were $24 \mathrm{~s}$ and $7 \mathrm{~s}$, the cooling time was $15 \mathrm{~s}$ for VZhM4. The mechanical properties for the alloy VZhM4 were taken from the paper [15]. The problem was solved in a quasi-static 3 -dimensional formulation. The boundary conditions were zero displacements in the direction of the $\mathrm{x}$-axis on two side faces of the sample with the normal along the $x$-axis. To exclude solid-state motions, a number of points on these faces in the direction of the $y$ and $z$ axes were also fixed (fig. 5).

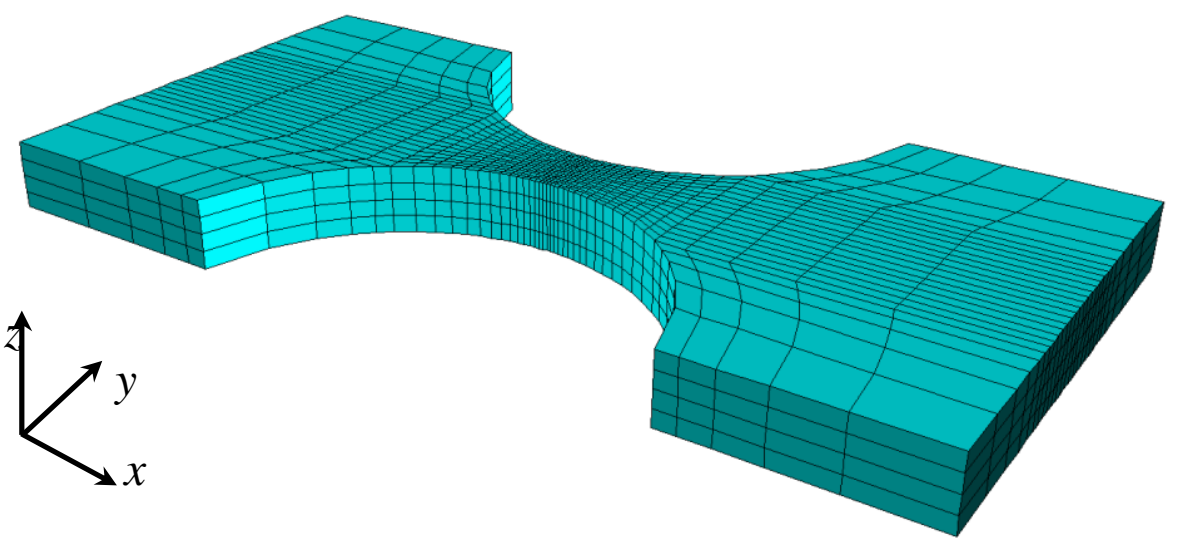

Fig. 5. Finite element model of sample (simplified formulation) for analysis of delay influence

Temperature evolutions in central point of sample with and without delay for thermal loading program $T=700 \div 1050{ }^{\circ} \mathrm{C}$ and $T=500 \div 1050{ }^{\circ} \mathrm{C}$ are presented in fig. 6 .
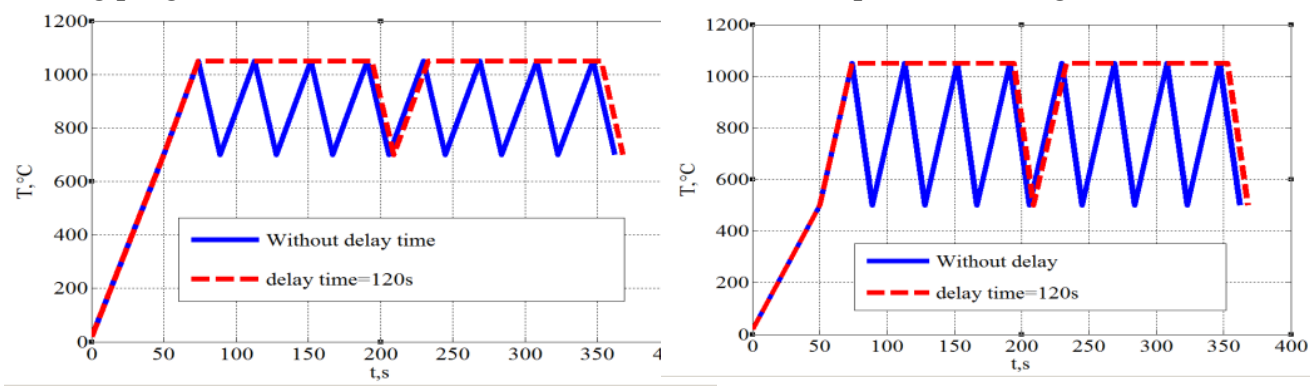

Fig. 6. Temperature evolutions in central point of sample with and without delay for $T=700 \div 1050{ }^{\circ} \mathrm{C}$ and $T=500 \div 1050{ }^{\circ} \mathrm{C}$.

Damage calculation and estimation of the number of cycles before the formation of macrocracks were made on the basis of deformation four-member criterion [7-11]:

$$
D=\sum_{i=1}^{N} \frac{\left(\Delta \varepsilon_{e q_{i}}^{p}\right)^{k}}{C_{1}(T)}+\sum_{i=1}^{N} \frac{\left(\Delta \varepsilon_{e q_{i}}^{c}\right)^{m}}{C_{2}(T)}+\max _{0 \leq t \leq t_{\max }} \frac{\varepsilon_{e q}^{p}}{\varepsilon_{r}^{p}(T)}+\max _{0 \leq t \leq t_{\max }} \frac{\varepsilon_{e q}^{c}}{\varepsilon_{r}^{c}(T)},
$$

where the first term takes into account the range of plastic strain within the cycle, the second term is the range of creep strain within the cycle, the third term is accumulated plastic strain 
(ratcheting), the fourth term is accumulated creep strain. The number of cycles before the formation of macrocrack $N$ is determined from the condition $D=1$. Usually it takes the values $k=2, m=\frac{5}{4}, C_{1}=\left(\varepsilon_{r}^{p}\right)^{k}, C_{2}=\left(\frac{3}{4} \varepsilon_{r}^{c}\right)^{m}$, where $\varepsilon_{r}^{p}$ and $\varepsilon_{r}^{c}$ are ultimate strains of plasticity and creep under uniaxial tension. In the FE computations the values of ultimate strain $\varepsilon_{r}^{p}=$ $\varepsilon_{r}^{c}=\varepsilon_{r}=0.17$ for VZhM4 were used.

Analytic approximation is offer to enter for describing of delay time influence on thermal fatigue strength. We consider the principle of deformation additivity in case of uniaxial loading:

$$
\varepsilon=\varepsilon_{e}+\varepsilon_{p}+\varepsilon_{c}+\varepsilon_{t}=\varepsilon_{0}
$$

where $\varepsilon$ is the full initial strain, $\varepsilon_{e}=\frac{\sigma}{E}$ is the elastic strain, $\varepsilon_{p}$ is the plastic strain, $\varepsilon_{c}$ is the creep strain and $\varepsilon_{t}$ is the temperature strain. Differentiation (2), using $\varepsilon_{p}^{\cdot}=\frac{\dot{\sigma}}{H}$, where $H$ is the hardening modulus [23], Norton law $\varepsilon_{c}^{\cdot}=\mathrm{A} \sigma^{n}$, taking into account $E+H=E_{T}$ is the tangent modulus [24] and dividing the equation by $\sigma^{n}$ we put:

$$
\sigma^{-n} \dot{\sigma}=-\mathrm{A} E_{T}
$$

Splitting variables, integrating from $t_{0}$ to time $\mathrm{t}$ and using $\dot{\varepsilon}_{c}=\mathrm{A} \sigma^{n}$ we put:

$$
\dot{\varepsilon_{c}}=A\left(\sigma_{0}^{1-n}+(n-1) A E_{T}\left(t-t_{0}\right)\right)^{\frac{n}{1-n}}
$$

Using variables changing $\tau=\sigma_{0}^{1-n}+(n-1) A E_{T}\left(t-t_{0}\right)$ and integrating from $t_{0}$ to time $t$ we obtain:

$$
\Delta \varepsilon_{c}=-\frac{1}{E_{T}}\left(\frac{1}{\left(\sigma_{0}^{1-n}+(\mathrm{n}-1) A E_{T}\left(t-t_{0}\right)\right)^{\frac{1}{1-n}}}-\frac{1}{\left(\sigma_{0}^{1-n}\right)^{\frac{1}{1-n}}}\right)=\frac{\sigma_{0}}{E_{T}}\left(1-\left(1+\frac{(\mathrm{n}-1) E_{T}}{\sigma_{0}} A \sigma_{0}^{n}\left(t-t_{0}\right)\right)^{\frac{1}{1-n}}\right)
$$

that leads to:

$$
\Delta \varepsilon_{c}=\frac{\sigma_{0}}{E_{T}}\left(1-\left(1+\frac{(\mathrm{n}-1) E_{T}}{\sigma_{0}} A \sigma_{0}^{n}\left(t-t_{0}\right)\right)^{\frac{1}{1-n}}\right)
$$

Using simplified deformation criterion with taking into account creep deformation terms:

$$
\frac{\varepsilon_{c}^{a c c u m u l}}{\varepsilon_{r}}+N\left(\frac{\Delta \varepsilon_{c}}{\varepsilon_{r}}\right)^{m}=1
$$

where $\varepsilon_{r}$ is the ultimate strain of creep under uniaxial tension, $N$ is the number of cycles of macrocrack initiation we obtain:

$$
N=\left(\frac{\varepsilon_{r}}{\frac{\sigma_{0}}{E_{T}}\left(1-\left(1+\frac{(\mathrm{n}-1) E_{T}}{\sigma_{0}} A \sigma_{0}^{n}\left(t_{\text {delay }}\right)^{\left.\frac{1}{1-n}\right)}\right.\right.}\right)^{m} *\left(1-\frac{\varepsilon_{c}^{\text {accumul }}}{\varepsilon_{r}}\right),
$$

In the simulations we use $E_{T}=8.2 \cdot 10^{4} \mathrm{MPa}, \sigma_{0}=\left(\alpha_{20-T \max } * T_{\max }-\alpha_{20-T \min } * T_{\min }\right) * E_{T} * 0.9$, $\alpha_{20-\text { Tmax }}$ and $\alpha_{20-\text { Tmin }}$ are the coefficients of linear thermal expansion, $A=10^{-}$ ${ }^{26} \mathrm{MPa}^{-n} S^{-1}, \quad \varepsilon_{r}=0.17$, multiplier $\left(1-\frac{\varepsilon_{c}^{a c c u m u l}}{\varepsilon_{r}}\right)$ picking up to correlate one point with experiment.

\section{Results and discussion}

The comparison of the results of FE simulations and experiments concerning the effect of the delay time at the maximum temperature on the thermal fatigue durability for single-crystal superalloys VZhM4 and is given in Fig. 7. 

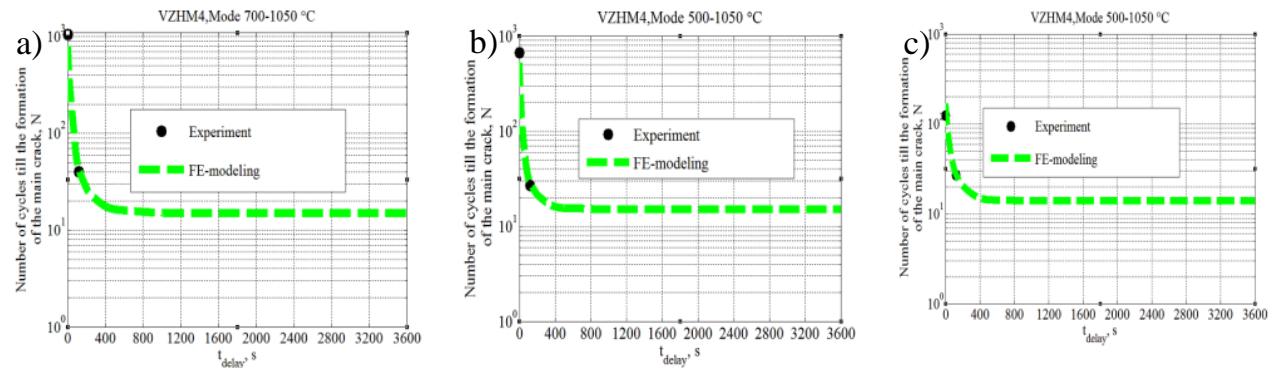

Fig. 7. Comparison of results of FE simulation and experimental data for alloy VZhM4: a) $\mathrm{T}=700 \div 1050{ }^{\circ} \mathrm{C}$, heating time is $7 \mathrm{~s}$, cooling time is $\left.15 \mathrm{~s}, \varepsilon_{r}=0.17, \mathrm{~b}\right) \mathrm{T}=500 \div 1050{ }^{\circ} \mathrm{C}$, heating time is $7 \mathrm{~s}$, cooling time is $15 \mathrm{~s}, \varepsilon_{r}=0.17$, c) T $=500 \div 1050{ }^{\circ} \mathrm{C}$, heating time is $24 \mathrm{~s}$, cooling time is $15 \mathrm{~s}, \varepsilon_{r}=0.17$.

Comparison of results of experiment and analytical approximation concerning the effect of the delay time at the maximum temperature on the thermal fatigue durability for singlecrystal superalloy VZhM4 is given in Fig. 8.
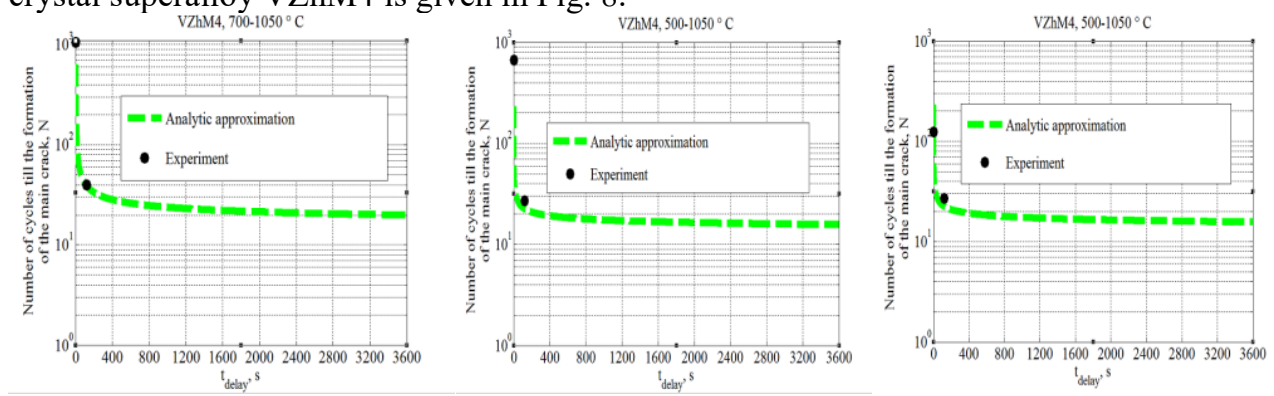

Fig. 8. Comparison of results of experiment and analytical approximation for alloy VZhM4: a) $T=700 \div 1050{ }^{\circ} \mathrm{C}$, heating time is $7 \mathrm{~s}$, cooling time is $15 \mathrm{~s}, \varepsilon_{r}=0.17$, b) $T=500 \div 1050{ }^{\circ} \mathrm{C}$, heating time is $7 \mathrm{~s}$, cooling time is $15 \mathrm{~s}, \varepsilon_{r}=0.17$,c) $T=500 \div 1050{ }^{\circ} \mathrm{C}$, heating time is $24 \mathrm{~s}$, cooling time is $15 \mathrm{~s}$, $\varepsilon_{r}=0.17$.

Note that the additive experimental verification is required for the near to horizontal branches of curves in fig. 7 and 8 corresponding to remarkable delays.

Influence of crystallographic orientation (CGO) on thermal fatigue strength for superalloys VZhM4 for two temperature modes is presented in fig. 9.
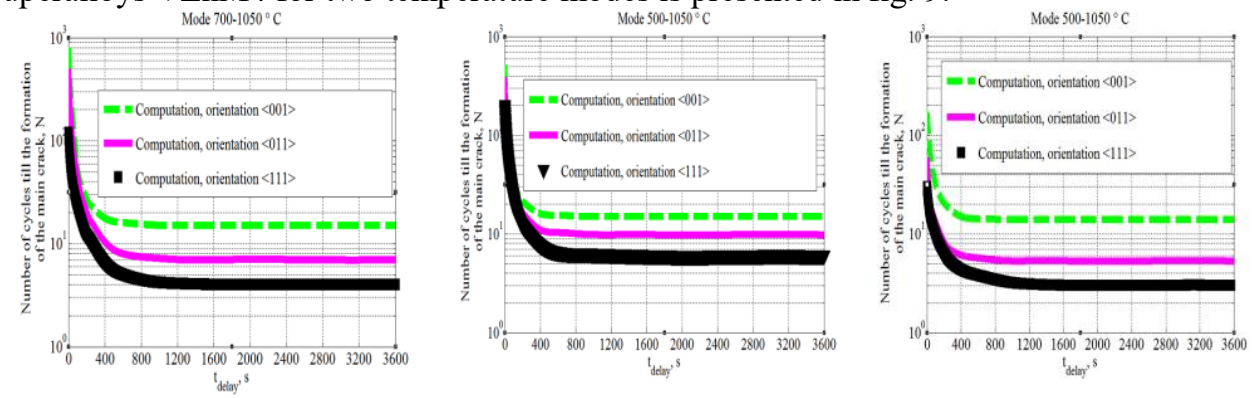

Fig. 9. Influence of crystallographic orientation on thermal fatigue strength for superalloy alloy VZhM4: a) $T=700 \div 1050{ }^{\circ} \mathrm{C}$, heating time is $7 \mathrm{~s}$, cooling time is $15 \mathrm{~s}, \varepsilon_{r}=0.17, T=500 \div 1050{ }^{\circ} \mathrm{C}$, heating time is $7 \mathrm{~s}$, cooling time is $15 \mathrm{~s}, \varepsilon_{r}=0.17$, c) $T=500 \div 1050{ }^{\circ} \mathrm{C}$, heating time is $24 \mathrm{~s}$, cooling time is $15 \mathrm{~s}, \varepsilon_{r}=0.17$. 
The thermal fatigue durability of samples from superalloy VZhM4 with CGO $<001>$ exceeds the thermal fatigue durabilities of $\mathrm{CGO}<011>$ and $<111>$ (fig. 9) for all considered loading programs.

Further improvement of the accuracy of thermal fatigue durability calculations with delays can be achieved by considering more complex creep models [25,26] and taking into account the rafting process [27] at high temperatures.

\section{Conclusions}

The results of the computations and the analytical approximations of delay-time influence on thermal fatigue durability show a good agreement with the experiment, which suggests that the finite-element and analytical computations in combination with application of deformation criterion (7) can be used to predict the thermal-fatigue strength of various singlecrystal superalloy samples with different delays. Researching of CGO influence has showed that thermal fatigue durability of specimens with crystallographic orientation $<001>$ is the highest among all considered variants and specimens with crystallographic orientation $<111>$ is the weakest among all variants of orientations.

The research is supported by RFBR grant No. 16-08-00845.

\section{References}

1. R.E. Shalin, I.L. Svetlov, E.B. Kachanov and other, Single crystals of nickel heatresistant alloys, 5, (1997).

2. E.N. Kablov, E.R. Golubovsky, Heat resistance of nickel-based alloys, 8, (1998).

3. J.A. Hojnicki, E.R. Golubovskiy, Strength of materials and resource elements of power equipment: Tr. CKTI, 296, 74-82 (2009).

4. R.A. Dulnev, P.I. Kotov, Thermal fatigue, 200 (1980).

5. Y.F. Balandin, Thermal fatigue of metals in ship mechanical engineering, 272 (1967).

6. L.B. Getsov, Materials and strength of gas turbine parts, 258-260 (2010).

7. L.B.Getsov, A.S. Semenov, Proceedings of CKTI, 296, 83-91 (2009).

8. A.S. Semenov, L.B. Getsov, Strength of Materials, 46, (1), 38-48 (2014).

9. L.B. Getsov, A.S. Semenov, A.A. Staroselsky, Materials and technology, 42, 3-12 (2008).

10. A.S. Semenov, L.B. Getsov, S.G. Semenov, Proc. XI all-Rus. Cong. on fund. prob. of theor. and ap. mech., 3408-3410 (2015).

11. L.B. Getsov, A.S. Semenov, I.A. Ignatovich, Inter. J. of Fat., 97, 88-97 (2017).

12. S. May, A.S. Semenov, Proc. of the XXXIX week of sc. of SPbGPU, 5, 73-74 (2010).

13. A.V. Savikovskii, A.S. Semenov, L.B. Getsov, Adv. probl. in mech.: proc. of the XLVI sum. sch.-conf., 228-238 (2018).

14. M.S. Gritskevich, A.V. Garbaruk, J. of Phys.: Conf. Series, 891(1) (2017).

15. E.N. Kablov, N.O. Petrushin, I.L. Svetlov, I.M. Demonis, Proc. of VIAM, 36-52 (2012).

16. S.B. Maslenkov, E.A. Maslenkova, Steels and alloys for high temperatures, 150 (1991).

17. A.S. Semenov, M.O. Beliaev, A.I. Grishchenko, PNRPU Mechanics Bulletin, 2, 153-177 (2017). 
18. V.Sh. Sufiiarov, A.A. Popovich, E.V. Borisov, I.A. Polozov, Tsvetnye Metally, 1, 77-82 (2017).

19. A.S. Semenov, Proc. of the V-th International. Conf. "Scient. and eng. probl. of reliab. and serv. life of str. and meth. of their decision", 466-480 (2003).

20. G.A. Cailletaud, Int. J. Plast., 8, 55-73 (1991).

21. A.S. Semenov, Scient. and tech. sh. SPbGPU. Phys. and math. Sc., 2 (194), 15-29 (2014).

22. P.V. Trusov, P.S. Volegov, N.S. Kondratyev, Perm: Publishing house Perm. NAT. research. Polytechnic. Un-ta, 244 (2013).

23. V.A. Palmov, E. Stain, Bulletin of Perm national research Polytechnic University, 9, 110-126 (2001).

24. A.S. Semenov, Computational methods in plasticity theory, 210 (2008).

25. N.A. Katanakha, A.S. Semenov, L.B. Getsov, Strength of Materials, 45 (4), 495-505 (2013).

26. A.S. Semenov, B.E. Melnikov, Procedia Engineering, 165, 1748-1756 (2016).

27. A.I. Grishchenko, A.S. Semenov, L.B. Getsov, Materials Physics and Mechanics, 24 (3), 325-330 (2015). 